\title{
A responsabilidade dos educadores
}

\section{Pontifícia Universidade Católica de Campinas}

BIESTA, Gert. Para além da aprendizagem: educação democrática para um futuro humano. Trad. Rosaura Eichenberg. Belo Horizonte, MG: Autêntica Editora, 2013. Título Original: Beyond Learning: Democratic education for a buman future.

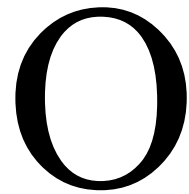

livro Para além da aprendizagem: educação democrática para um futuro humano, de Gert Biesta, é o resultado do somatório de inúmeros artigos, capítulos de livros e apresentações do autor.

Assim reunidas, tais ideias pretendem figurar como uma teoria da educação, outro modo de pensá-la, contudo a obra é toda construída sobre o pensamento de outros autores que serão destacados ao longo dessa resenha.

$\mathrm{O}$ autor deixa claro que, mesmo em se tratando de um livro que é embasado em teorias filosóficas, não se dirige a teóricos e sim aos educadores para que estes, ao final da leitura, possam basear suas práticas educacionais e responder, por si mesmos, às questões propostas no texto.

No prólogo, Biesta trata da complexa questão da definição de ser humano e humanidade e coloca que, acima de tudo, essa questão é posta em sua obra no âmbito educacional. Dessa forma, a educação traz a ideia de intervir na vida das pessoas e torná-las seres humanos mais agradáveis, proporcionando sua aderência ao ambiente sociocultural. Entretanto, tomando apenas esse ponto de vista, a educação pode excluir e reproduzir desigualdades. Portanto, ela deveria ter como tarefa disciplinar, treinar e socializar moralmente a humanidade do indivíduo.

No primeiro capítulo, intitulado "Contra a aprendizagem: recuperando uma linguagem para a educação numa era da aprendizagem”, Biesta deseja contribuir para uma linguagem de educação que parte da premissa de que essa mesma educação influencia no que pode ser dito e feito, ultrapassando 
a linguagem da aprendizagem, enquanto recupera a linguagem da educação para a educação. $\mathrm{O}$ autor postula que o conceito de educação foi engolido pelo de aprendizagem, que tornou-se, agora, o centro da educação. Gert Biesta nos apresenta, então, o surgimento da nova linguagem da aprendizagem, que deve ser compreendida, como poderá ser observado adiante, como uma série de diferentes desenvolvimentos não intencionais da sociedade, dividida em quatro tipos: a primeira linguagem é aquela que trata da aprendizagem construída pelo próprio educando; a segunda diz respeito à educação como herança do Iluminismo, embasada no pensamento racional e crítico; uma terceira interfere na educação adulta por meio de diversos canais formais e não formais de educação e a última é aquela ligada à erosão do estado de bem-estar social. O ponto positivo das linguagens encontra-se em seu impacto nas práticas educacionais e no aumento de oportunidades para a aprendizagem. Nesse sentido, é melhor estar com ela do que sem. Porém, essa nova forma de aprendizagem está ligada ao pensamento neoliberal, a partir do momento em que passa a ser tratada como uma troca econômica, ou seja, os pais - ou o educando - compram o tipo de educação que pretendem que seus filhos tenham, pagando, em troca, determinado valor. Biesta não ignora nem descarta a ideia de que as pessoas podem escolher o que querem aprender e o que querem para si e seus entes, contudo não demonstra sua opinião a esse respeito na obra.

Dessa forma, porém, a educação se sujeita ao mercado, tornando-se importante propor questões educacionais para a educação. Assim, no decorrer do capítulo, o autor apresenta o que seriam tais questões educacionais, investigando a forma como os seres podem vir ao mundo único e singular por meio das relações educacionais embasadas em três conceitos, como exposto a seguir. $\mathrm{O}$ conceito da confiança diz respeito às relações educacionais permeadas de riscos e desafios nesse sentido: o aluno 
pode aprender o que ele busca, aprender além do que esperava e ainda adquire conhecimentos tais que ele não queria ou não estava esperando aprender; à luz desse viés, o educando tem consigo apenas a confiança, pois não tem ideia do que vai aprender, uma vez que o aprendizado pode ir além de suas expectativas e dos conteúdos programáticos oferecidos ou vendidos a ele. O segundo conceito é o da violência transcendental, segundo o qual a educação tem relação com o externo, que interfere de forma contundente na vida dos estudantes. Essa interferência se dá de forma metafísica entre o aluno e o professor: o primeiro recebe aquilo que é externo a si por meio do seu mestre e responde aquilo que lhe foi transmitido; é esse o sentido de violência proposto pelo autor. No terceiro conceito, o de responsabilidade, o autor argumenta que os educadores não têm conhecimento dos educandos pelos quais ele deve se responsabilizar e não tem clareza a respeito daquilo que resultará dessa influência. Dessa forma, a responsabilidade do professor é, de acordo com Biesta, sem limites, tornando-se impossível que ele saiba o que tal responsabilidade acarretará no futuro de seus alunos.

Biesta passa, então, a construir sua visão da educação desconsiderando-a como um processo de produção da subjetividade e de sujeitos racionais autônomos, considerando necessário, para isso, superar o humanismo enraizado na educação. $\mathrm{O}$ autor começa o segundo capítulo sugerindo, como modo de realizar essa superação na educação, o abandono da ideia de sujeito humano, o que não significa que defenda o fim do homem. Aqui, Biesta critica a ideia do humanismo e sua pretensão de definir em que consiste a humanidade dos seres humanos, colocando-se como crítico da ideia de que se pode definir a essência do que é ser humano à luz de tal proposição; pensa que, no lugar de se buscar a essência do ser humano, seria melhor perguntar onde o ser humano, como indivíduo único, se torna presente, não em sua presença física, mas sim como um ser singular

Filosofia e Educação [rfe] - volume 7, número 1 - Campinas, SP

Fevereiro-Maio de 2015 - ISSN 1984-9605 - p. 173-180 
entre outros seres únicos, considerando que essa presença, essa chegada ao mundo, não acontece isoladamente. Para que se dê a introdução de um ser no mundo, é necessário que outros assumam esses inícios de forma imprevisível, sem traçar a vida do primeiro, afirma Biesta, amparado nos conceitos de Hannah Arendt. Pois é só assim que um novo ser pode iniciarse em um mundo já povoado por outros iniciadores, um mundo de pluralidade e diferenças, onde só poderemos agir se os outros também forem capazes de assim fazê-lo. Assim, de Emmanuel Levinas, o autor empresta a ideia central de espaço intersubjetivo para a acolhida de novos inícios, noção segundo a qual o estar-no-mundo primordial é um estar-no-mundo-comoutros, concluindo que somos com o outro antes de sermos com nós mesmos.

Ponto de destaque na obra do autor é a compreensão de um mundo de pluralidade, apresentada no terceiro capítulo. Biesta dá partida com a definição de comunidade, concebida por Alphonso Lingis como um grupo constituído por vários indivíduos que possuem algo em comum e constroem algo em comum, e destaca um caso comum de comunidade, a racional, que é constituída por uma linguagem comum e uma lógica comum, incumbidas da tarefa de dar voz às pessoas, uma voz representativa, ou seja, aquela alicerçada na lógica e na linguagem dessa comunidade.

Por conseguinte, no capítulo 4 Biesta procura compreender o que é vir a um mundo repleto de outros que não são como nós e destaca que o que nos torna únicos e singulares é a subjetividade, é justamente a maneira como interagimos com os outros que são outros, pautando-se em Hannah Arendt, novamente, para tratar do assunto.

Do pensamento arendtiano, Biesta destaca dois pontos: o primeiro é aquele que diz respeito à nossa impossibilidade de vir ao mundo sendo nós mesmos senhores únicos do que fazemos, ou seja, a nossa vinda ao mundo 
depende da atividade de outros que adotarão nossos inícios no mundo; o segundo ponto refere-se à afirmação de Arendt de que a liberdade só existe em ação com os outros. Só somos livres quando estamos com os outros, de modo que só somos livres num espaço mundano de pluralidade e diferença. Percebe-se que o autor apenas se posiciona ante os conceitos apresentados pela filósofa e, não apresentando contribuições significativas, dá a impressão de apenas parafrasear Arendt.

O capítulo 5, "A arquitetura da educação: criando um espaço mundano", a princípio, nos parece um tanto estranho dentro da obra ou ainda nos leva a crer que o autor vai tratar de um aspecto abstrato. Todavia, o conceito de arquitetura não se mostra apenas no sentido metafísico, o que causa um pouco de falta de clareza durante a leitura. Ao contrário, Biesta nos remete a um espaço físico e busca na arquitetura encontrar o espaço mais próximo daquele pertinente à pluralidade e à diferença. Para pontuar uma analogia entre a arquitetura e a educação, visando dizer o que é responsabilidade e o que ela acarreta, Biesta traz conceitos da bildung (termo alemão comumente traduzido em Inglês como "edificação") conceito absorvido da construção e traduzido para o Português também como edificação. Essa tradição deve originar respostas conceituais a desafios particulares como aquele da responsabilidade educacional, que para o filósofo tem a ver com a criação do espaço mundano já citado. Cabe salientar que Biesta sinaliza que a arquitetura tem um caráter funcionalista e que é importante que os arquitetos escapem desse funcionalismo, mas que, ao assim fazerem, devem abdicar da arquitetura. Voltando-se para um approach abstrato e citando Derrida e seu conceito de desconstrução daquilo que vemos, lemos e ouvimos, o autor afirma que o dever da arquitetura é estar preocupada com os espaços e os eventos que ali 
ocorrerão, necessitando para o projeto, todavia, transgredir na abstração acerca desses aspectos, mais uma vez a confusão entre concreto e abstrato.

Biesta pensa que o educador também deve amparar a vinda de seres únicos e singulares ao mundo. Porém, se a vinda desses recém-chegados, segundo o conceito criado por Arendt, que caracteriza o ser humano como um "initium", ou seja, um início e um iniciador ao mundo dependem de espaços mundanos plurais e diferentes, cabe ao educador a criação desses espaços. Gert Biesta demanda aos educadores e professores que o que rompe a comunidade racional pode ser justamente o ponto em que os estudantes começam a encontrar sua própria voz, única, responsiva e responsável. Sendo assim, a responsabilidade do educador não pode ser conhecida de antemão, visto que o educador não conhece aquilo pelo qual é responsável. Então, viemos ao mundo como seres únicos e singulares pela maneira como assumimos as diferenças dos outros e as interpretamos por nossa própria voz e não pela voz da comunidade racional.

Logo chegamos ao último capítulo, intitulado "A educação e a pessoa democrática", que focaliza o papel da educação numa sociedade democrática e que, portanto, tem a ver com a concepção de pessoa democrática, sendo este, a nosso ver, o capítulo mais próximo do cotidiano e mais fácil de ser compreendido, ilustrando-se no dia a dia do professor e do estudante.

Biesta apresenta três respostas diferentes para o que seja uma pessoa democrática: uma individualista, conforme Immanuel Kant, que afirma que essa pessoa é aquela que pode pensar por si mesma, e por isso o sujeito kantiano é racional e autônomo, cabendo nesse caso, à educação democrática, liberar o potencial racional do sujeito humano. Biesta busca com seu conterrâneo, John Dewey, ilustrar a concepção social de pessoa democrática, uma alternativa à subjetividade kantiana. Para Dewey, a 
interação é essencial, sendo que a comunicação se dá numa via de mão dupla, num processo prático em que padrões de ações são transformados comumente. Dewey não nega aos seres humanos a capacidade de pensar e refletir por si sós, o que ele questiona é que esse dom seja inato, defendendo que só nos tornamos o que somos por meio de nossa participação em um ambiente social. A terceira concepção de subjetividade da pessoa democrática, a concepção política, é ilustrada sob a influência do pensamento de Hannah Arendt e deve ser compreendida como uma qualidade da interação humana, ficando clara a preferência do autor por essa linha de pensamento, que é considerada por ele como aquela que fornece fundamento lógico para abordar a educação democrática, embora considere e sublinhe o pensamento deweyano. Para o autor, Hannah Arendt postula que a corrente que sustenta que a educação democrática deve ser aquela que prepara os estudantes e os recém-chegados para a participação democrática.

Aqui onde retomamos o pensamento de Arendt, a educação deve deixar de ser entendida como algo que acontecerá mais tarde, para ser o espaço onde os indivíduos podem agir e introduzir-se no mundo como sujeitos democráticos, desde o começo. Todavia, as escolas devem ter um ambiente educacional propício para oportunizar de forma real o contato do educando com a democracia. Biesta não mostra como construir a escola ideal para a educação democrática, afirmando ser uma tarefa árdua exercer uma educação que possa ser assimilada como democrática pelo aluno, esclarecendo ele próprio que suas sugestões nesse sentido são gerais e abstratas.

No epílogo, Biesta conclui que a responsabilidade dos educadores é aquela pelo que vai acontecer, sem ter conhecimento do que vai acontecer e de quem vai chegar (quem será o recém-chegado). Em vista disso, fica claro o título do livro - Para além da aprendizagem -, pelo qual Gert Biesta quer 
apresentar para os educadores uma proposta que vá além do saber ler, escrever, desenhar etc., sem desconsiderar a importância dessas práticas e da aprendizagem, mas frisando que, para ele, a escola não deve restringir-se a isso, aspirando à formação de indivíduos únicos e singulares, destinados a se tornarem-se sujeitos democráticos, contudo a obra é totalmente calcada no pensamento e nos conceitos de outros autores que aqui foram reagrupados sob o olhar de Gert Biesta, inclusive no confuso capítulo 5, "A arquitetura da educação: criando um espaço mundano". Destaca-se, deste modo, que é essa a principal contribuição do autor ou, dependendo de como o leitor debruçar-se sobre o livro e interpretá-lo, o ponto fraco da obra de Biesta, ou seja, trazer à tona os conceitos e posicionamentos de outros filósofos e estudiosos (Derrida, Dewey, Kant, Arendt, Levinas e Lingis) ao mesmo tempo em que se utiliza do pensamento deles para embasar a sua obra e estruturar o seu conceito de uma educação "para além da aprendizagem" calcada na democracia, para a inserção no mundo de indivíduos críticos e únicos. 